\title{
EFFECT OF THE NATURE OF THE ELECTROLYTE AND THE NATURE OF THE INTERFACE ON THE HYDROGEN EVOLUTION POTENTIAL: EXPERIMENTS FOR CHEMISTRY STUDENTS
}

\author{
Silvia Maria Leite Agostinho*,a, ${ }^{(1)}$, Ruth Flavia Vera Villamil Jaimes ${ }^{\mathrm{b}}$, Lucas Vairolette ${ }^{\mathrm{c}}$ and Isis Valença de Souza Santos \\ Instituto de Química, Universidade de São Paulo, 05508-000 São Paulo - SP, Brasil \\ ${ }^{b}$ Centro de Ciências Naturais e Humanas, Universidade Federal do ABC, 09210-580 Santo André - SP, Brasil \\ 'Faculdades Oswaldo Cruz, 01151-000 São Paulo - SP, Brasil
}

Recebido em 24/10/2018; aceito em 19/12/2018; publicado na web em 11/02/2019

\begin{abstract}
This work presents an experiment done for chemistry students about the effect of the nature of the electrolyte and the nature of the interface on the hydrogen evolution reaction by electrolysis. Two techniques are suggested: method A - two identical copper electrodes in a direct current circuit and method B - three different electrodes in a dc potentiostatic circuit, with copper electrode (working), platinum electrode (counter) and silver-silver chloride- $\mathrm{KCl}$ sat electrode (reference). The hydrogen evolution was observed using the A technique by increasing potentials between the two electrodes and the visual observation of the gas production at the cathode. The results showed "semi-quantitative" effect of the $\mathrm{pH}$ on the hydrogen evolution. It was observed a larger potential difference in alkaline medium than in acid medium. The results obtained with the B technique from polarization curves showed quantitatively the thermodynamic effect of the $\mathrm{pH}$ in addition to the least catalytic effect of copper presented in alkaline medium when compared to copper in acid medium for hydrogen evolution. The technique A can be used in technical courses, high school and general chemistry class for under graduate students. The technique B is appropriate for under graduate electrochemistry class and graduate students.
\end{abstract}

Keywords: hydrogen evolution; electrolysis; thermodynamic and kinetic effect; experiment proposal.

\section{INTRODUCTION}

Hydrogen is the most abundant element in the universe. It is estimated that hydrogen accounts for about $90 \%$ of the universe atoms. Hydrogen production is often integrated with chemical processes requiring $\mathrm{H}_{2}$ as feedstock. ${ }^{1,2}$

Historically, hydrogen has been of great importance since the experiments of Cavendish, in 1766, who was the first to isolate and study the physical properties of this substance. Observing that it exploded when heated in contact with the air, he called it "flammable air". Chemist Joseph Priestley realized that after the explosion, the experiment tube was damp on the walls. ${ }^{2}$ Cavendish investigated the formed matter and proved that water was a compound of oxygen and hydrogen ${ }^{2}$. The French chemist Antoine Lavoisier, in 1783, repeated the Cavendish experience and gave the name hydrogen for the resulting gas.

Hydrogen is a dangerous gas because it can initiate fires. Its invisible flame can cause serious burns.

The main use of hydrogen is in direct combination with $\mathrm{N}_{2}$ to produce $\mathrm{NH}_{3}$ (Haber process), the primary source of compounds containing nitrogen, as plastics and fertilizers. Hydrogen gas is also important in fuel cells. ${ }^{2,3}$ In a simplified version of a fuel cell, a fuel, such as hydrogen gas, passes over a platinum electrode, the oxygen gas passes through another electrode and the electrolyte is a solution of potassium hydroxide in water. A porous membrane separates the compartments of two electrodes. Hydrogen is applied as protection gas in welding processes, as tracker for leaks. The hydrogen gas is applied in food industries as well.

The hydrogen gas preparation usually consists of the reduction of the $\mathrm{H}^{+}$ion obtained by spontaneous chemical reaction or by electrolysis. Electrolytic hydrogen, commercially the purest form, is obtained by water electrolysis in different electrolytes, in acid, neutral or alkaline media. However, hydrogen gas preparation

*e-mail: smlagost@iq.usp.br from electrolysis is expensive: the high overvoltage of the reaction in different electrochemical systems causes high cost of electric energy. ${ }^{3,4}$

In laboratories, the action of metals immersed in acid or alkaline solutions produces hydrogen, for example:

metals in acid medium

$$
\mathrm{Fe}_{(s)}+2 \mathrm{H}_{(a q)}^{2+} \rightarrow \mathrm{Fe}_{(a q)}^{2+}+H_{2(g)}
$$

metals in alkaline medium

$$
4 \mathrm{Al}_{(s)}+4 \mathrm{OH}_{(a q)}^{-}+12 \mathrm{H}_{2} \mathrm{O} \rightarrow 4 \mathrm{Al}(\mathrm{OH})_{4(a q)}^{-}+6 \mathrm{H}_{2(g)}
$$

The production of hydrogen by spontaneous chemical processes involving the oxidation of a metal is possible if the reduction reaction of $\mathrm{H}^{+}$ions presents a reduction potential more positive than the reduction potential of the metallic ion considered. Iron, zinc, magnesium, tin, are examples of metals that react spontaneously with hydrogen ion. Copper, silver, mercury and gold are examples of noble metals that do not react spontaneously with hydrogen ion to produce hydrogen gas. Some amphoteric metals, as aluminum and zinc can produce hydrogen in alkaline media from reduction of water.

Hydrogen can be obtained not spontaneously by electrolysis. ${ }^{4}$ The cathodic reaction can be represented by one of the equations, in aqueous media:

$$
2 H_{(a q)}^{+}+2 e^{-} \rightarrow H_{2(g)} \quad \mathrm{E}^{0}=0.00 \mathrm{~V} / \mathrm{SHE}
$$

or

$$
2 \mathrm{H}_{2} \mathrm{O}_{(l)}+2 e^{-} \rightarrow \mathrm{H}_{2(g)}+2 \mathrm{OH}_{(a q)}^{-} \quad \mathrm{E}^{0}=-0.83 \mathrm{~V} / \mathrm{SHE}
$$

The potential values in equations (3) and (4) represent the standard state potential in acid and alkaline media, respectively. 
The hydrogen evolution also depends on kinetic factors. It is possible to consider two aspects: the nature of the metal, used as electrode and the nature of the metal-solution interface. Trassati ${ }^{5}$ have shown the dependence of change current density of the hydrogen evolution reaction on metal-hydrogen bond energy in the respective metallic hydride. Volcan plots were constructed, where platinum is in the top, as can be seen from the reference cited.

The authors suggest a theoretical introduction to experimental part B involving electrochemical kinetics. It is important to introduce Butler-Volmer equation and the concepts of equilibrium potential, overvoltage, change current density and standard change current density. It is important, also, the discussion about corrosion potential and the mean of polarization curves. These concepts can be followed by Volcan plots 5 to show the standard change current density values for the equilibrium $\mathrm{H}^{+} / \mathrm{H}_{2}$ on different electrodes.

\section{OBJECTIVES}

The aims of this work are:

- study the effect of the nature of the electrolyte and the nature of the interface on the hydrogen evolution potential;

- propose an experiment that leads high school, technical courses and general chemistry students to observe the $\mathrm{pH}$ effect on the electrochemical hydrogen evolution on copper electrode;

propose experiments that lead undergraduate or graduate students to understand the different thermodynamic and kinetic factors that affect the electrochemical hydrogen evolution on copper electrode.

\section{EXPERIMENTAL PROCEDURE}

Two techniques were employed: A - two identical electrodes of copper in a dc circuit and B - three different electrodes in a dc potentiostatic circuit, with copper electrode (working), platinum electrode (counter) and silver-silver chloride- $\mathrm{KCl}$ sat electrode (reference). Figure 1 presents the schematic representation of the electrochemical system used in A and B procedures.

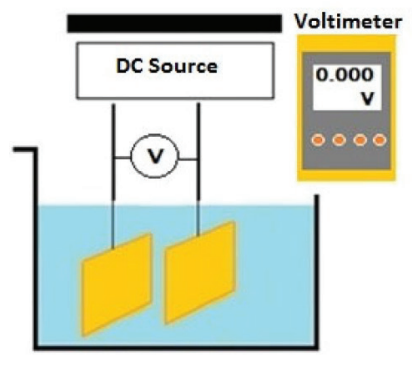

(a)

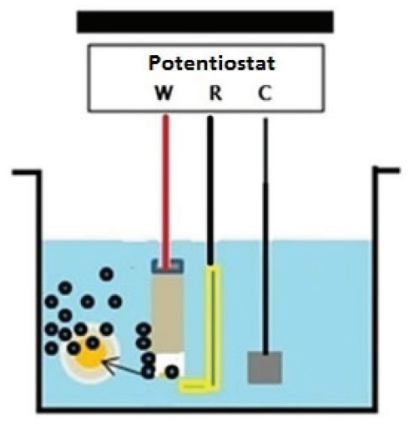

(b)
Figure 1. Schematic representation of the electrochemical system: (a) using two identical electrodes (copper), a direct current source and a voltmeter, $0.001 \mathrm{~V}$ precision for the potential difference evaluation and (b) at controlledpotential, with three electrodes in a potentiostatic circuit, copper electrode (working, W), platinum electrode (counter, $\mathrm{C}$ ) and silver-silver chloride- $\mathrm{KCl}$ sat electrode. (reference, $R$ )

\section{Technique A -Visual analysis}

Increasing potential differences were applied between the two copper electrodes. Two stationary electrolytic copper electrodes $\left(6 \mathrm{~cm}^{2}\right.$ of geometrical area) were employed in electrochemical measurements. The hydrogen evolution reaction was observed at the most negative copper electrode, the cathode.

The minimum potential difference for hydrogen production was considered to be the one in which the gas evolution was visually observed. The other copper electrode, the anode, presented the copper oxidation reaction to $\mathrm{Cu}^{2+}$ ions, evidenced by the appearance of the blue colour in the solution.

\section{Technique B - Graphical analysis}

The potential was applied through a potentiostat which is a device capable to control the electrical potential between the working electrode (copper) and the reference electrode. A $0.18 \mathrm{~cm}^{2}$ copper disk, a saturated $\mathrm{Ag} / \mathrm{AgCl} / \mathrm{KCl}$ sat and a large area platinum foil were used as working, reference and auxiliary electrodes, respectively. It was used a boron-silicate electrolytic cell ( $50 \mathrm{~mL}$ volume). The working electrode surface was successively polished with emery papers of 600 and 1200 mesh and then thoroughly rinsed with distilled water prior to the experiments. Analytical grade reagents and deionized water were used to prepare the solutions.

The silver-silver chloride electrode- $\mathrm{KCl}$ sat, presents a potential $\mathrm{E}=-0.199 \mathrm{~V}$ relative to standard hydrogen electrode. It was used a computer controlled AutoLab III potentiostat in the electrochemical measurements. All the experiments were conducted with naturally aerated solutions at $(25.0 \pm 0.5){ }^{\circ} \mathrm{C}$. Prior to each experiment, the electrodes were immersed in the electrolyte until the attainment of the quasi stationary open circuit potential. Cathodic polarization curves were registered, and the hydrogen evolution potential was graphically evaluated (quantitative analysis).

There is a potential difference between the metal and the solution measured in relation to the reference electrode. This potential difference names open circuit potential. Curves of the open circuit potential as a function of time for the copper electrode in $1 \mathrm{~mol} \mathrm{~L}^{-1}$ sulfuric acid and $1 \mathrm{~mol} \mathrm{~L}^{-1}$ sodium hydroxide media were registered to evaluate the quasi stationary value of the open circuit potential, within the experimental error, named corrosion potential $\left(\mathrm{E}_{\mathrm{corr}}\right)$, before to obtain the polarization curves.

It is important to note that in aerated media, the copper is not stable. The reactions involved can be described below:

$$
\begin{array}{cc}
\text { In acid media, } & \text { In alkaline media, } \\
\mathrm{Cu}_{(s)} \rightarrow \mathrm{Cu}_{(a q)}^{2+}+2 e^{-} & 2 \mathrm{Cu}_{(s)}+2 \mathrm{OH}_{(a q)}^{-} \rightarrow \mathrm{Cu}_{2} \mathrm{O}_{(s)}+2 e^{-}+\mathrm{H}_{2} \mathrm{O}_{(l)} \\
1 / 2 \mathrm{O}_{2(g)}+2 \mathrm{H}^{+}+2 e^{-} \rightarrow \mathrm{H}_{2} \mathrm{O}_{(l)} & \mathrm{Cu}_{2} \mathrm{O}_{(s)}+3 \mathrm{H}_{2} \mathrm{O}_{(l)} \rightarrow 2 \mathrm{Cu}(\mathrm{OH})_{2(s)}+2 e^{-}+2 \mathrm{OH}_{(a q)}^{-} \\
& 1 / 2 \mathrm{O}_{2(g)}+\mathrm{H}_{2} \mathrm{O}_{(l)}+2 e^{-} \rightarrow 2 \mathrm{OH}_{(a q)}^{-}
\end{array}
$$

And they correspond to a condition of non-equilibrium, where the process is irreversible, the potential is the corrosion potential and in this potential the current is the corrosion current.

\section{RESULTS AND DISCUSSION}

\section{Technique A}

Table 1 shows the results for copper electrode assays on different electrolytes. It was performed three measurements for each solution. Mean values of potential difference are presented in Table 1 .

It is observed that the hydrogen evolution reaction $2 \mathrm{H}_{(\mathrm{aq})}^{+}+2 \mathrm{e}^{-} \rightleftharpoons \mathrm{H}_{2(\mathrm{~g})}$ is thermodynamically favoured by the decrease in $\mathrm{pH}$, that is, the more acid the medium, the lower the potential difference. ${ }^{6}$ It is impossible, using only two electrodes, to compare the experimental potential difference with that value obtained from 
Table 1. Effect of the nature of the electrolyte through a visual analysis

\begin{tabular}{cc}
\hline Electrolyte $\left(1 \mathrm{~mol} \mathrm{~L}^{-1}\right)$ & Potential difference $/ \mathrm{V}$ \\
\hline $\mathrm{H}_{2} \mathrm{SO}_{4}$ & $0.606 \pm 0.008(3)$ \\
$\mathrm{NaOH}$ & $1.06 \pm 0.02(3)$ \\
\hline
\end{tabular}

thermodynamic data because there are kinetic aspects to be considered at the cathode, where the hydrogen evolution occurs and at the anode, where copper is oxidised to copper (II) ions. This experiment is semi quantitative but it shows the change of the potential when the $\mathrm{pH}$ is changed.

\section{Technique B}

The following values were obtained for the quasi stationary open circuit potential after 4 minutes: $-0.005 \mathrm{~V}$ and $-0.002 \mathrm{~V}$ in acid and basic media, respectively. These potential values can be considered the corrosion potential of copper in the two media $\left(\mathrm{E}_{\text {corr }}\right)$.

It is assumed that the current passing in the circuit between the working electrode and the reference electrode, connected to the voltmeter, is very low, due to the high electrical impedance of this instrument.

Figure 2 shows a cyclic polarization curve for the copper electrode in $1 \mathrm{~mol} \mathrm{~L}^{-1} \mathrm{H}_{2} \mathrm{SO}_{4}$ medium from the quasi stationary open circuit potential, $\mathrm{E}_{\text {corr }}$.

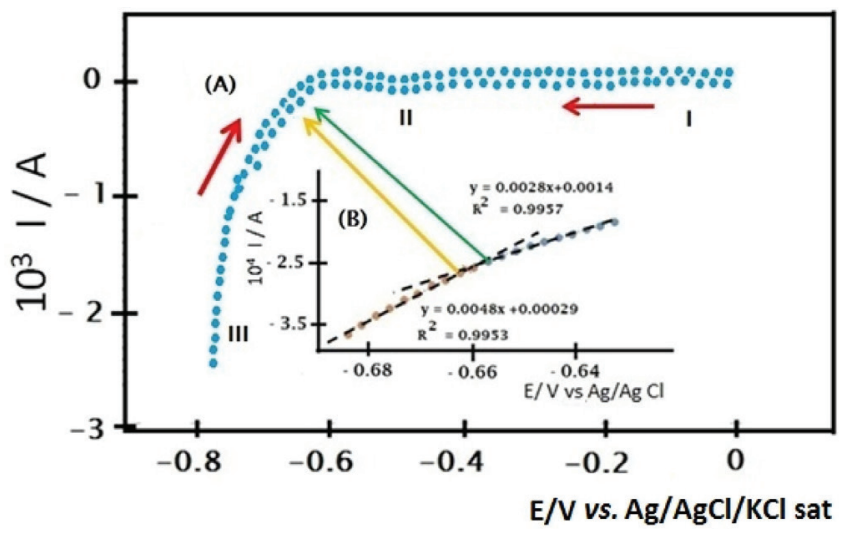

Figure 2. Cathodic polarization curve of the copper electrode in $1 \mathrm{~mol} \mathrm{~L}^{-1}$ $\mathrm{H}_{2} \mathrm{SO}_{4}$ medium. Scan rate $=1 \mathrm{mVs}^{-1}$ (curve A) and potential regions chosen to determine the hydrogen evolution potential (curve B)

A cathodic polarization scan was performed, that is, in the direction of negative potentials until the potential $-0.8 \mathrm{~V}$ (vs Ag / $\mathrm{AgCl} / \mathrm{KCl}$ sat) followed by an anodic scan, that is, in the direction of positive potentials from $-0.8 \mathrm{~V}$ ( $\mathrm{vs} \mathrm{Ag} / \mathrm{AgCl} / \mathrm{KCl}$ sat) until the corrosion potential, $\mathrm{E}_{\text {corr }}{ }^{7-9} \mathrm{In}$ the direction of the cathodic sweep (most negative potentials), a current very close to zero in the stretch I is observed. The peak observed at around $-0.5 \mathrm{~V}$ (vs Ag / AgCl/KCl sat) can be attributed to the reduction of the dissolved oxygen in the solution, according to the electrode reaction equation:

$$
2 \mathrm{H}_{(a q)}^{+}+1 / 2 \mathrm{O}_{2(g)}+2 e^{-} \rightarrow \mathrm{H}_{2} \mathrm{O}
$$

As the potential becomes more negative, there is an abrupt increase in the current in the stretch II. This increase can be attributed to the reaction of hydrogen evolution from $\mathrm{H}^{+}$ions, according to the electrode reaction equation:

$$
2 H_{(a q)}^{+}+2 e^{-} \rightarrow H_{2(g)}
$$

It is important to observe two aspects:

according to the thermodynamic potential values the oxygen is reduced to less negative potentials than the $\mathrm{H}^{+}$ion;

- according to the kinetic data, the current due to oxygen reduction is very low because its concentration in solution is less than 10 mmol L-1. The sudden increase of the current at more negative potentials, where the hydrogen detachment occurs, is due to the high concentration of $\mathrm{H}^{+}$in the solution $\left(1 \mathrm{~mol} \mathrm{~L}^{-1}\right)$.

The extension of the oxygen reduction curve and the beginning of the hydrogen evolution curve were extrapolated and their intersection determined, as shown in Figure 2B. The two lines had a correlation coefficient very close to 1 .

It was considered ten points of each linear region and calculated the equation of the straight lines and in the interception of the two straight lines, the potential of hydrogen evolution was determined.

Figure 3 shows the cathodic polarization of copper in alkaline medium.

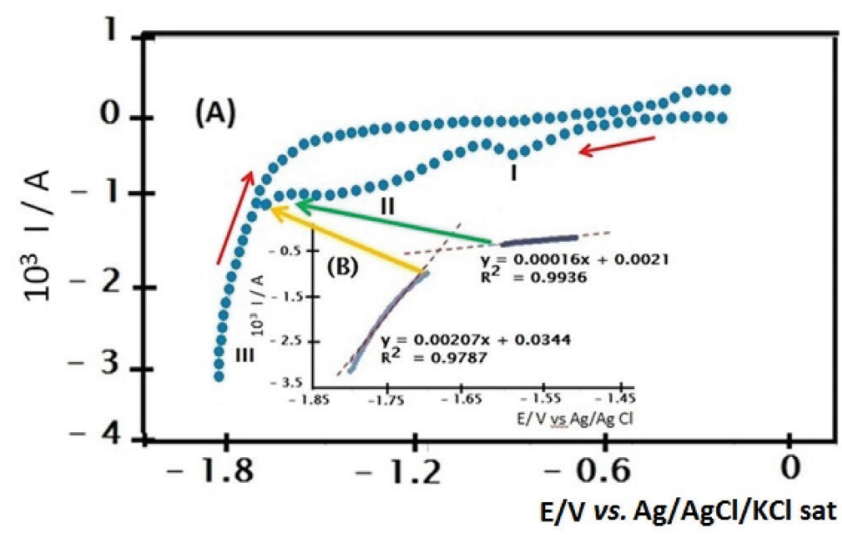

Figure 3. Cylic voltammetry of the copper electrode in $1 \mathrm{~mol} \mathrm{~L}^{-1} \mathrm{NaOH}$ medium. Scan rate $=1 \mathrm{mVs}^{-1}$ (Curve A) and regions chosen for analysis of hydrogen evolution (curve B)

Figures $3 \mathrm{~A}$ and $3 \mathrm{~B}$ show the polarization curves of copper in sodium hydroxide. Copper is not stable in alkaline medium containing oxygen: copper oxides and copper (II) hydroxide are formed on corrosion potential. Two peaks are identified in the cathodic sweep. The peak I, at less negative potentials is due to the reduction of cuprous oxide $\mathrm{Cu}_{2} \mathrm{O}$ and the second, peak II, is due to the reduction of cupric oxide, $\mathrm{CuO}$, or copper (II) hydroxide, $\mathrm{Cu}(\mathrm{OH})_{2} \cdot{ }^{10,11}$

It is possible to notice in these curves that the hydrogen evolution happens when there is a great increase of potential of the working electrode in the negative direction.

In order to determine the potential of hydrogen evolution, the calculation used was through two straight lines, where ten points before and ten points after the release of hydrogen were used, which was considered the beginning of elevation (in modulus) of the current in the cathodic polarization curve after reduction of cupric oxide.

These peaks are not perceived when the metal is immersed in sulfuric acid solution, since the copper remains as copper (II) ions in solution, it does not present oxides on its surface detectable by this technique..$^{10,12}$

Although the concentration of $\mathrm{H}^{+}$ions in $1 \mathrm{~mol} \mathrm{~L}^{-1} \mathrm{NaOH}$ equals to $10^{-14} \mathrm{~mol} \mathrm{~L}^{-1}$, the high current elevation is due to the high concentration of water equal to $55.5 \mathrm{~mol} \mathrm{~L}^{-1}$. Remember that it is possible to replace the reaction

$$
H_{(a q)}^{+}+e^{-} \rightarrow 1 / 2 H_{2(g)}
$$


by the reaction:

$$
\mathrm{H}_{2} \mathrm{O}_{(l)}+e^{-} \rightarrow^{1 / 2} \mathrm{H}_{2(g)}+\mathrm{OH}_{(a q)}^{-}
$$

It suffices to add to the first equation the ionic equilibrium of water, given by:

$$
H_{2} \mathrm{O}_{(l)} \rightleftharpoons H_{(a q)}^{+}+O H_{(a q)}^{-}
$$

Table 2 presents the mean value of hydrogen evolution potentials obtained from analytical method.

Table 2. Effect of the nature of the electrolyte on the hydrogen evolution potential on copper

\begin{tabular}{cc}
\hline Electrolyte $\left(1 \mathrm{~mol} \mathrm{~L}^{-1}\right)$ & Potential (V) \\
\hline $\mathrm{H}_{2} \mathrm{SO}_{4}$ & $-0.66 \pm 0.01(3)$ \\
$\mathrm{NaOH}$ & $-1.70 \pm 0.02(3)$ \\
\hline
\end{tabular}

In sulfuric acid medium, on the $\mathrm{Ag} / \mathrm{AgCl} / \mathrm{KCl}$ sat electrode scale the thermodynamic potential of the hydrogen electrode should be $-0.199 \mathrm{~V}$. The value $-0.66 \mathrm{~V}$ indicates that the reaction on the copper electrode presents an overvoltage due to a kinetic effect. This reaction on copper is slower than on platinum / platinized, chosen for the standard hydrogen electrode, considered a reversible electrode. $i_{00}$ values have magnitude order on platinum equal to $10^{-2} \mathrm{~mA} \mathrm{~cm}^{-2}$ while on copper is equal to $10^{-5} \mathrm{~mA} \mathrm{~cm}^{-2}$ as can be seen from Volcan plot. ${ }^{5}$

If the interface was $\mathrm{Cu} / \mathrm{Cu}^{2+}{ }_{(a q)}$, the potential difference between these two media would be $-0.83 \mathrm{~V}$. What is the reason?

First, the thermodynamic potential of the hydrogen electrode can be calculated. In an acidic medium, $\mathrm{pH}=0$, its potential is $0.0 \mathrm{~V}$, corresponding to standard hydrogen electrode potential. In alkaline medium, $\mathrm{pH}=14$, its potential is calculated as follows.

Admitting the electrode equation:

$$
H_{(a q)}^{+}+e^{-} \rightarrow 1 / 2 H_{2(g)}
$$

Applying the Nernst equation

$$
E=E^{0}+0.059 \log a_{H+} / P_{H 2}^{1 / 2}
$$

Considering $\mathrm{n}=1$ (number of electrons involved), in $1.0 \mathrm{~mol} \mathrm{~L}^{-1}$ $\mathrm{NaOH}$ medium $a_{H+}=10^{-14} \mathrm{~mol} \mathrm{~L}^{-1}$, therefore,

$$
E=0+0.059 \log 10^{-14}
$$

$\mathrm{E}=-0.83 \mathrm{~V}$ on the standard electrode scale of hydrogen, or $\mathrm{E}=-1.02 \mathrm{~V}$ on the $\mathrm{Ag} / \mathrm{AgCl} / \mathrm{KCl}$ sat electrode scale employed. The practical potential observed in alkaline medium was equal to $-1.70 \mathrm{~V}$.

If the displacement were only thermodynamic, this difference should give $0.83 \mathrm{~V}$ in module. The greater difference can be attributed to: the presence of copper oxides on the surface of this metal in alkaline medium, resulting in another interface, a less effective catalyst than copper; the mechanism of the hydrogen evolution reaction is different in acid medium, where $\mathrm{H}_{3} \mathrm{O}^{+}$ion is reduced when compared to alkaline medium, where water molecules are reduced on the metallic surface. In other words, the greater difference in modulus is due to the kinetic effect. Bockris and Reddy ${ }^{10}$ suggest examples of mechanisms:

- in acid medium the hydronium ion is reduced on the metallic surface and produces adsorbed $\mathrm{H}$ atoms, $\mathrm{M}-\mathrm{H}_{\text {(ads) }}$ (equation 12).
It is supposed that for copper the rate determining step is the second step given by equation $13 .{ }^{10,12}$

$$
\begin{gathered}
\mathrm{H}_{3} \mathrm{O}^{+}+\mathrm{e}^{-} \rightarrow \mathrm{H}_{2} \mathrm{O}_{(\mathrm{l})}+\mathrm{M}-\mathrm{H}_{(\mathrm{ads})} \\
\mathrm{M}-\mathrm{H}_{(\mathrm{ads})}+\mathrm{H}_{3} \mathrm{O}^{+}+\mathrm{e}^{-} \rightarrow \mathrm{M}+\mathrm{H}_{2}+\mathrm{H}_{2} \mathrm{O}
\end{gathered}
$$

in alkaline medium water molecule is reduced on the metallic surface producing $\mathrm{H}$ atoms and hydroxyl ion

$$
\mathrm{H}_{2} \mathrm{O}_{(l)}+e^{-} \rightarrow \mathrm{H}_{(a d s)}+\mathrm{OH}_{(a q)}^{-}
$$

This step is followed by the reaction (15).

$$
H_{(a d s)}+H_{(a d s)} \rightarrow H_{2}
$$

It is not objective of this work to discuss the mechanism of hydrogen evolution reaction on copper.

The following question may arise: Why are there copper oxides on the surface if they were reduced in the cathodic sweep?

When the polarization is made in the anodic direction, a current increasing is observed at potentials close to the corrosion potential, indicating the re-oxidation of the metallic copper to copper oxide. In addition it is worth to remember that the reduction of the oxides was done through a potential scan, which does not guarantee that all the oxide has been reduced. The electrolysis was not exhaustive.

\section{CONCLUSIONS}

It was possible to show qualitatively and quantitatively the thermodynamic effect of the nature of the electrolyte and the kinetic effect of the nature of the electrolyte and the nature of the interface on the hydrogen evolution potential.

From the thermodynamic point of view in acidic environment hydrogen production occurs at a less negative potential compared to alkaline medium.

From the kinetic point of view, several observations were made: - The copper electrode is worst catalyst with respect to a platinized platinum electrode maintained the same $\mathrm{pH}$ of the solution, as presented in the literature.

- The copper oxides present on copper surface show that in alkaline medium the hydrogen evolution potential is more negative than thermodynamically expected suggesting that the interface $\mathrm{Cu} / \mathrm{Cu}^{2+}{ }_{(\mathrm{aq})}$ present in an acid medium is a better catalyst than the interface $\mathrm{Cu} /$ copper oxides.

From the point of view of teaching electrochemistry, it is suggested that the experiment $\mathrm{B}$ is applied in disciplines of physical chemistry or electrochemistry for undergraduate or graduate students. The semi quantitative experiment $\mathrm{A}$ applies to the discipline of general chemistry for graduate student, at high school and technical courses, because it contains a smaller number of concepts.

\section{ACKNOWLEDGEMENTS}

The authors would like to thanks to Conselho Nacional de Desenvolvimento Cientifico e Tecnológico (CNPq) for financial support.

\section{REFERENCES}

1. Lee. J. D.; Concise Inorganic Chemistry, $4^{\text {th }}$. ed., Chapman \& Hall: London, 1999.

2. Atkins, P. W.; Jones, L.; Chemical Principles: The Quest for Insight, $3^{\text {rd }}$ ed., W. H. Freeman \& Co.: New York, 2007. 
3. Koryra J., Dvorák, J.; Kavan, L.; Principles of Electrochemistry, $2^{\text {nd }}$ ed., Wiley: Hoboken, 1993, pp. 352.

4. Ticianelli, E. A., Gonzales, E. R.; Eletroquímica, Edusp: São Paulo, 1998, pp. 191-197.

5. Trasatti, S.; J. Electroanal. Chem. 1972, 39, 163.

6. Chang, R.; Química Geral: Conceitos Essenciais, McGraw-Hill: New York, 2007, pp. 646-649.

7. Souza, K. S.; Jaimes, R. F. V. V.; Rogero, S. O.; Nascente, P. A. de P.; Agostinho, S. M. L.; Braz. Dent. J. 2016, 1, 191.
8. Villamil, R. F. V.; Corio, P.; Rubim, J. C.; Agostinho. S. M. L.; J. Electroanal. Chem. 1999, 472, 112.

9. Villamil, R. F. V.; Corio, P.; Rubim, J. C.; Agostinho. S. M. L.; J. Electroanal. Chem. 2002, 535, 75.

10. Bockris. J. O'M.; Reddy, A. K. N.; Electroquímica Moderna, Editorial Reverté, S. A.: Barcelona, 1980, pp. 1297-1317.

11. Brotto, M. E.; Iha, K.; An. Assoc. Bras. Quim. 1996, 45, 73.

12. Hibbert, D. B.; Introduction to Electrochemistry, Macmillan International Higher Education: London, 1993, pp. 179-180. 